\title{
Juvenile Crime: Current State and Dynamics
}

\author{
Nikoli V. Valuiskov ${ }^{1}$, Lubov V.Bondarenk ${ }^{2} \&$ Ani D. Arutiunian ${ }^{3}$ \\ ${ }^{1}$ candidate of law sciences, associate professor, Don State Technical University, Rostov Region, Shachty, \\ Shevchenko st., 147, Russia \\ ${ }^{2}$ candidate of economic sciences, associate professor, Don State Technical University, Rostov Region, Shachty, \\ Shevchenko st., 147, Russia \\ ${ }^{3}$ Assistant, Don State Technical University, Rostov Region, Shachty, Shevchenko st., 147, Russia \\ Correspondence: Nikoli V. Valuiskov, candidate of law sciences, associate professor, Don State Technical \\ University, Rostov Region, Shachty, Shevchenko st., 147, Russia. E-mail: valuiskov58@mail.ru
}

Received: June 19, 2017

doi:10.5539/jpl.v10n4p225
Accepted: July 18, $2017 \quad$ Online Published: August 30, 2017

URL: https://doi.org/10.5539/jpl.v10n4p225

\begin{abstract}
The article presents a comprehensive analysis of the problems of general and individual juvenile delinquency prevention. The definition of «general social crime preventive action» is given, its objectives and types are defined. The necessity of investing efforts and resources not in the repressive programs, but in the fundamental long-term programs aimed at the gradual elimination of social and economic disparities being the cause of the increase in crime rate among teenagers. The components and targets of individual crime prevention have been identified. The individual subjects of the juvenile crime prevention have been classified. The requirements for the subjects of the individual criminal behavior prediction have been formulated in order to create the theoretical and organizational prerequisites for the reliability of the individual behavior forecasts. As a result, the special measures of juvenile delinquency prevention have been proposed.
\end{abstract}

Keywords: crime, juvenile, juvenile law, crime prevention

\section{Introduction}

Despite the efforts of the state and society efforts to establish systems of protection of the rights of minors and young people, there is a steady increase of child abandonment, vagrancy, an increasing number of minors and persons of young age, suffering from alcoholism, drug addiction, toxicomania, tobacco Smoking. Against this background, recorded a negative change in the level of juvenile crime. In fact, today every eleventh-twelfth the convicted person has not reached the age of majority. Worse and qualitative characteristics of juvenile crime: a growing proportion of serious organized crime committed with particular cruelty, with a deadly weapon. The state of juvenile crime requires the development of adequate measures to counter it.

\section{Methods}

In this paper used General scientific methods (analysis and synthesis, modeling, system approach, comparative, historical, lo-cal, etc.) and especially scientific (special) methods.

\section{The Main Part}

According to statistics, in January - May 2016 previously investigated crimes committed by juveniles or with their complicity total for the Russian Federation - 21862.

Consideration of problems of General and individual prevention of juvenile crime is closely linked to the clarification of the space that they occupy in the system of measures of crime prevention.

Speaking about the prevention of juvenile delinquency should be borne in mind that there are many types, which are allocated depending on the entities involved in prevention activities, as well as from certain characteristics of the object of this activity.

Directly, depending on the entities involved in measures to prevent the Commission of crimes, the nature of these measures distinguish between General social and specially-criminological prevention.

In criminological literature, it was noted that some important measures to prevent crimes, eliminate the causes that generate them, not have as their direct objective the prevention of illegal behavior (Shlyapochnikov, 1972). 
«It is a sign of focus in the formulation and solution of tasks distinguishes the field of crime prevention from a preventive action of the most General processes of social development which is «incidentally» in the course of solving the broader social value» (Minkovsky, 1972).

General social prevention of crime - determining subsystem of the process of crime prevention. It covers the most extensive long-term and effective types of social activities, the most significant social action (Sadkov, 1994). The purpose of the General Social prevention is the elimination, neutralization, weakening the entire complex criminogenic factors; prevention of the possibility of the formation of the antisocial orientation of the individual; the prevention of criminogenic consequences of economic and social activities.

In the modern current economic and social tensions in the society, the crisis of ideology, complicating the process of education, General social prevention of juvenile delinquency is limited.

General measures are not designed for a one-time exercise. However, not to underestimating the role and importance of general social prevention, we consider it necessary to consider the main directions of specially-criminological prevention, in particular, individual prevention of juvenile delinquency. Especially warning-criminological closely linked to the general social prevention, which, on the one hand, it is for the foundation determines its direction and the actual content, and on the other - the very feeling the effects of a specially-criminological prevention.

A.E. Zhalinsky defined the nature of the interaction between one and the other kinds of crime prevention: «... their effects on - the phenomena that give rise to crime and mutually summed up in the implementation, they are intertwined» (Zhalinsky, 1976).

The juvenile may implementation of prevention, at different stages of criminalization.

It is necessary to distinguish several types of early, to prevent the commission of crimes by persons who have committed administrative offenses, the prevention of recurrence. Activities especially - of criminological prevention of offenses should focus primarily on early warning (early prevention). Of particular interest is the fact that in criminological science at an early and immediate split both general and individual crime prevention.

Direct individual prophylaxis is carried out, if we are talking about the possibility of the commission of the offense or any other person, «deals» with the person from whom you can realistically expect to crime. In the field of early prevention, as outlined in the criminological literature, gets the personality, «characterized negatively, located, however, on the stage, speaking conditionally, even remote from the commission of the crime» (Avanesov, 1984).

Thus, it should be to conduct a system of measures to ensure the improvement of the living conditions and upbringing of minors; combating and elimination of the sources of anti-social actions impact on them; the impact on juvenile «deviant» behavior, preventing the consolidation of their minds and behavior of anti-social attitudes and habits.

At present include: the elimination of the adverse conditions of life and education, especially in the family; elimination of shortcomings in the work of bodies involved in the training and education of children and adolescents; impact on people, negatively affecting minors; activation of the legal and educational propaganda and much more (Pankratov, 1983).

Researchers concerned with the prevention of juvenile delinquency, noted that in a particular territorial level directly and immediately to the task involved 40 different in nature and subordination of state bodies, institutions, enterprises, public organizations and individual officials and citizens. They plan and implement a variety of preventive features, including the integration of material and resource support for this activity, identify minors, in respect of which requires the use of preventive measures, identify people, negatively affecting their education, carry out individual work on the identification and correction of offenders, preventive work with them parents and other persons who are adversely affecting the education of children and adolescents (Sundurov, 1983).

Large quantity indicators the total number of participants in education and prevention activities at first glance, give reason to assume a high availability of the necessary capacity and capabilities. However, the absence of significant changes in the status and trends of juvenile delinquency entitles reveal defects and to identify ways to further improve the activities of the state in the legal regulation of this activity. Today, scientists have noted that the number of juvenile prevention entities acting permanently reduced by one-third. However, their area of activity has become more specialized than preventive.

Some areas of work with juveniles become carried out on a commercial basis. There are no important areas of prevention: ideological, patriotic, political (Pishikina, 1998). 
Scientists in most countries with different levels of economic development and different political regimes have come to the conclusion that investing manpower and resources is not a specific repression of the program, and in the fundamental long-term program aimed at the gradual elimination of social and economic ills of society, is the cause of adverse development of the criminal situation (Korolenko, 1999).

Interests combating crime involve a complex effect on all aspects of its components, however, are currently in the Russian Federation, this approach is complicated by heavy criminal situations caused by the stratification, the fall of the prestige of law enforcement agencies, worsening the legal protection of the population, the almost complete disappearance of social prevention and many other factors.

Accordingly, based on the specific contingent of juvenile offenders, their social status and other characteristics that affect their criminal behavior, the conclusion about the absolute necessity of the prevalence of preventive measures applied to these individuals (especially early warning) on measures of a punitive action.

Currently, the researchers note that the societal level, prevention should be as early as in the process of its implementation is not interrupted genesis of criminal behavior and eliminating the very possibility of its occurrence (Criminal motivation, 1986).

Immediately, in the scientific and theoretical point of view, the fight against juvenile delinquency should be regarded as a system of general measures and specific warnings.

On the basis of the presence or absence of a real possibility of committing a crime by a specific person has an individual and general crime prevention.

General crime prevention measures aimed at addressing the complex causes and conditions of criminal behavior in any sphere of life, at a certain object, etc. regardless of the specific individuals who may commit crimes. That is why the measures of influence on the person, not specifically aimed at preventing the commission of a crime cannot be attributed to an individual on the prevention of crimes. Their objective property prevents broadly person committing the crime is, in our view, the basis of their reference to measures of general crime prevention as their direct purpose is different from the individual crime prevention purposes.

Warning of individual criminal behavior consists of:

- individual crime prevention, whose objectives are the prevention of criminal behavior on the part of those crimes that is really possible, and the gradual elimination of the subjective prerequisites of the individual criminal behavior of specific individuals;

- plotting and prevent prepared crimes, which is aimed at preventing the commission of offenses by persons a real opportunity to commit crimes that is specified in terms of appearance design to commit a specific crime, pondering and planning their own criminal activities, the selection of instruments of crime, etc.;

- preventive began crimes, prevent crimes started bringing to the end.

Consequently, the components of crime prevention at the individual level reflect the activities to prevent the commission of offenses by persons in various stages of subjective readiness to commit a crime (Kirillov, 1994).

The objectives of the individual crime prevention are:

- preventing criminal behavior of persons from whom the commission of crimes is really possible;

- such a change of personality of these individuals, which would have eliminated a real opportunity to commit their crimes and created the preconditions for sustainable non-criminal behavior in the future.

The above allows to determine the scope of an individual crime prevention, highlighting its following features:

- All measures of individual crime prevention «aimed» to a particular person;

- to the sphere of individual crime prevention should include measures aimed at preventing criminal behavior of the person;

- all measures of individual prevention of crimes are interrelated, and synergies between the merged into a single complex.

These signs of the scope of the individual crime prevention define the limits of the study as an individual prevention of crime in general and with respect to minors.

In the criminological literature offers a variety of approaches to the disclosure of the content of individual crime prevention. Some authors suggest the definition of the individual crime prevention in the form of wording, others - in the form of disclosure of the content of individual crime prevention, others formulate the most important, in their view, the features and characteristics of individual crime prevention. 
Individual prevention of juvenile crime can be defined as a set of measures specifically aimed at preventing criminal behavior of minors, feasible on the part of which is the commission of crimes and change the personality traits that cause a real opportunity to commit their crimes.

In the criminological literature to refer to the real possibility of the commission of the offense or any other person, the terms «anti-social orientation of the person» (Avanesov, 1984), «the crime deformity personality» (Igoshev, 1977) and others.

It is believed that these concepts are not entirely correctly identified. This is due mainly to the fact that the identity of all persons, from which you can really expect to commit crimes, cannot be characterized by such features as a social focus and the crime deformation, as these signs, in our view, the lack of identity of the actual possible from which an unwary committing crime.

Thus, persons who need to use the individual prevention of crime, are individuals from whom you can realistically expect to crime. As for the term «antisocial personality», «criminogenic improperly formed personality» etc., is, in our view, these terms are useful only for the characteristics of the person, from which the real possibility of committing an intentional crime.

Often the development trend of personality indicates the formation of a real possibility of committing crimes specific person. In relation to such persons should apply measures aimed at preventing the formation of a real opportunity to commit their crimes. If such measures are not taken to be, the real possibility of the person the crime apparently formed.

However, to include such measures in a complex individual prevention of crime, in our opinion, should not be, because the question of the real possibility of committing a crime is not yet. Such measures should be included in the complex of early prevention measures, which are carried out in the framework of social control, and within the framework of special measures of law enforcement agencies, including law enforcement bodies.

First of all, you must understand what is the object of individual prevention of juvenile crime.

Interesting, though not an indisputable point of view expressed by A.P.Zakalyuk. He shared the object and subject of individual crime prevention. Under the object understood specific individuals - carriers causes of individual criminal behavior and microenvironment, and under the subject - specific constituent elements, both individuals and the microenvironment, which is sent directly to a preventive effect (Zakalyuk, 1986) ... We will not analyze it in detail, but shall confine ourselves just mention the fact that it exists. At the same time, it must be noted that the author as an individual object of crime prevention and suggests considering the microenvironment, immediate surroundings of the minor.

D.A. Kirillov offers a more careful definition. He believes that the main targets of individual prevention of crimes are persons committing crimes on the part of that is really possible, optional objects of individual crime prevention are factors that may adversely affect the profilaktiruemyh (Kirillov, 1994).

We believe that if, in speaking of the immediate environment of a minor involve dysfunctional family, teenagers, youth group, they will be subject to a group of prevention of juvenile delinquency.

Under the Group prevention of juvenile delinquency is proposed to understand the application of general and special-Criminal action against a group of persons, including the united family relationships, individual or group whose members generally commit antisocial acts or offenses.

In our view, under the subject of individual prevention of juvenile crime should be understood minors (children, adolescents and young people) who commit antisocial acts and offenses, including crimes, as well as minors, offenses by which realistically possible.

Obviously, the formal recognition of the person profilaktiruemym should take place only when there are grounds for inclusion criminological person to circle the individual objects of crime prevention. Therefore, the terms «profilaktiruemy» and «individual prevention of crime object» correspond, in our view, as the form and content.

Signs, on the basis of which a citizen or an organization can be attributed to the circle of subjects of individual crime prevention are:

- Immediate course of action of a social element to achieving the goals of the individual crime prevention;

- Inclusion of this element in the individual subjects of crime prevention;

- Coherence individual citizen or organization with the requirements of the individual subjects of the system of prevention of crime;

- The relative independence of a particular social element in the implementation of individual measures of crime 
prevention.

We carry out a classification of subjects of individual prevention of juvenile crime:

- Organizations and individuals, the main function of which is the activity of individual prevention of juvenile crime;

- Organizations and individuals for whom the individual prevention of juvenile crime is one of the main activities;

- Organizations and individuals in the functional responsibilities include the implementation of individual prevention of juvenile crime, but who carry out some of its measures.

The subject of individual prevention of juvenile crime is an organization or a citizen, whose activities are directly aimed at achieving the objectives of individual prevention of crimes of minors included in the system of social elements, carrying out individual prevention of juvenile crime, matching to the requirements of this system and have under these relative independence requirements the implementation of individual measures of prevention of juvenile crime.

Preventive work in general and individual prevention of juvenile delinquency is conducted by employees in accordance OPPN, the latest requirements of the Interior Ministry, the Internal Affairs PO Guidelines in conjunction with other services, as well as in cooperation with the departments concerned. So, in the Rostov region holds quarterly interdepartmental meeting with the prosecutor of the city, which deals with issues related to the prevention of juvenile delinquency, are revealed shortcomings and omissions in this direction. Particular attention is paid to the prevention of the crime group, dissociation to form groups and work with especial contingent of minors.

Questions state of juvenile delinquency in the Rostov region considered at the enlarged meeting of the regional, city and district commissions for minors with the participation of schools and colleges of directors. The decisions marked deficiencies in the organization of preventive work.

Over the years, repeatedly held events such as the «Teenager», «Vortex-2» in which it was revealed a significant number of minors, unlawful leading lifestyle and need help from the state.

Individual events were covered in the local press and were shown on local television.

General and individual prevention in the Rostov region with persons who are registered in OPPN, carried out in accordance with the requirements of the Ministry of Interior Orders № 180-88, № 186-93, № 390-93, and in accordance with the instructions of RA Police.

For example, in this study, we have investigated the Internal Affairs reports on the prevention of juvenile crime in the city of Mines. On the preventive supervision in the departments of Internal Affairs in 1997 consisted PPN. 609 people, including 65 people who have criminal records, 158 persons committed socially dangerous acts before attaining the age of criminal responsibility in 1998. - 610 people, including 30 people who have criminal records, 150 persons committed socially dangerous acts before attaining the age of criminal responsibility. In 1999- 564 people, including 46 people who have criminal records, 173 persons committed socially dangerous acts before attaining the age of criminal responsibility.

The disadvantages in carrying out preventive work with persons who have registered, you can include unplanned, formalism, lack of interaction with other services. The main and the main drawback is that there is still no proper interaction with the security officer ESD juvenile due to the fact that they are virtually eliminated from the problems of juvenile delinquency, and engaged in other matters in connection with which lost many positive things have occurred previously in close cooperation and exchange of information. However, the results would be much better if the cooperation of all services in full conformity with the requirements. Despite the fact that this issue was put to a meeting of the permanent-existing operational meeting with the chief of the police department, he was not removed from the agenda.

However, the activity OPPN achieved certain results. So OPPN ATC has made that dismissal of students from schools takes place only through the commission on juvenile affairs. If it is necessary, through the employment center made attempts of employment of teenagers.

Head of the Administration issued a decree on obligatory employment quotas socially vulnerable strata of the city population, including teenagers. However, due to the fact that the city is not hiring anyone state-owned enterprise in the current year, it was possible to employ only 17 people from among the registered in OPPN. The lack of adequate legal protection of minors in the workplace leads to a rise in crime among this category of persons. 
Analysis of individual preventive activities of internal affairs bodies leads to the conclusion that one of the biggest drawbacks has been its often unjustified use of this or that individual measures of individual crime prevention. This is due, in our opinion, the fact that, at first, the conclusion about the real possibility or impossibility of committing a crime, or the other person is carried out, as a rule, intuitively (Zakalyuk, 1989; Criminology and crime prevention, 1989; Valuiskov et al., 2012; Arutynyan and Valuiskov, 2014), so far not in all cases possible to speak about the reliability of such a conclusion. Secondly, it should be noted that in any normative act, and even more so in the law, there is no clear regulation of the grounds and procedure for the designation of a person to circle the individual objects of crime prevention. Third, few employees of internal affairs bodies of practice on the use of personal prevention of crime, thinks about the validity or invalidity of each particular case «attribution» of a person to circle the individual objects of crime prevention.

One of the urgent problems of crime prevention is the issue of the reasonableness of assigning citizens to individual objects around crime prevention.

This problem occurs when deciding on the setting on the registration of a person, which is to become a kind of «filter», which, on the one hand, does not allow to carry a range of profilaktiruemyh persons who are not subject to an individual crime prevention, and on the other side maximum fostering integration in the sphere of individual prevention of all those crimes, by which is a real possibility.

It is very important to avoid undue involvement of citizens in the sphere of individual prevention of crime, since at present to the public the process of protecting the rights and legitimate interests of citizens is of the great importance of the problem.

This will be possible if the basis of a set of legal norms regulating the relations in the formulation of individual prevention facilities crimes registered in the bodies of internal affairs as one of the principles is the principle of reasonableness pravoogranicheny persons «attributed» to the circle of objects of individual crime prevention.

A decision on the need to apply to a particular person crime prevention should be based on the forecast of the possible commission of crimes face.

Intuitive forecast - is also forecast, and it is on the basis of these, as a rule, forecasts and currently adopted in most cases the decision on the use of organs of internal affairs of individual crime prevention measures to specific individuals, but, as noted above, such solutions sin unfounded.

Therefore, it would be better to say that the decision on the application of measures to face the individual crime prevention should be based on a reliable forecast. Ensuring the implementation of such a forecast reliability requirement due, in our opinion, due to the necessity of organization of procedure predict individual behavior.

After all, in essence, the prognosis of individual behavior should be the basis of the origin of relations, ie, legal fact. Based on this fact, it seems that the prediction procedure should be based on a fixed standard, the scientifically based method of predicting an individual; as well as a specially created system of specialized subjects of individual prediction.

We know that scientifically sound methods to predict individual behavior have already been created, and there are quite successful results of their testing in practice. So, a lot of work on the development of diagnostic methods and the individual prediction of individual behavior has been carried out at the turn of 70-80-iesInstitute of Ministry of Internal Affairs of the USSR (Abizov, 1979). The question is how to actually implement this kind of procedure in individual preventive activities of internal affairs bodies.

As for the subject of the prediction of individual criminal behavior, there is, in our opinion, it is necessary that it meets two major requirements.

Firstly, the subject must have a special competence in the field of scientific prediction of individual criminal behavior.

Secondly, it must be «subordinate neutral» with respect to the bodies and officials interested in the final results of individual crime prevention.

Implementation of these two requirements will create a theoretical and organizational prerequisites reliability of the forecasts of individual behavior.

The system of subjects of prediction must be generated by the type system of expert departments. In this particular case, the system of constituent entities of individual forecasting could be called units, are individually and prognostic examination. Undoubtedly, the establishment of such units and maintaining them would require certain material costs. However, on the other hand, as a result of the operation «units individually predictive expertise» is just able to create the same «filter» that would be involved in the sphere of individual crime 
prevention those and only those persons who commit crimes on the part of which is really possible. In addition, the accumulation of these offices work experience, their ability can be used not only in matters of the spheres of individual crime prevention.

For example, over time the data units could turn into a multi-purpose unit diagnosis and prognosis of a person and his ability might be used as a reference to the different areas of the fight against crime, and in other spheres of life. A reliable forecast of individual criminal behavior, presented by independent and competent entities should be, in our opinion, the only basis for inclusion of a particular person to circle the individual objects of crime prevention.

The next problem is to determine the range of the prediction of subjects.

On the one hand, the prediction of individual behavior in itself is to some extent a violation of the rights and legitimate interests of citizens; therefore requires certain conditions under which the behavior of a particular person may be subject to individual prediction.

On the other hand, excessive and unwarranted expansion of the circle of persons whose behavior becomes the object of an individual prediction entails unnecessary material costs.

It is necessary, in our opinion, the presence of certain circumstances in which the behavior of a particular person would be subject to individual prediction. These circumstances must be such, that would not extend over the range of persons whose behavior is predicted, and at the same time, as much as possible those crimes, by which is a real possibility to engage in a procedure for forecasting individual criminal behavior.

It seems that the circumstances in which the prediction of individual behavior in order to identify the real possibility of committing minor offenses terminology can be described as conditions of recognition of a person to circle the individual objects of crime prevention. It is necessary, in our opinion, their standard fastening, and, above all, because it is a limitation of the rights and legitimate interests of minors.

\section{Discussion}

For example, consider one of these conditions. So, before the release of a specific person from prison almost always solved by the application or non-application to that person an individual crime prevention measures (in particular, the establishment of administrative supervision) after serving the sentence. So far, this problem is solved on the basis of the intuitive forecast.

The release of a person from prison should be a condition referring to the circle of his personal objects prevention of crime, condition predicting its behavior. If the forecast will contain a conclusion about the real possibility of a crime the person is released from the IUT, then this person must be after the release of the application of measures of individual crime prevention.

Thus, the condition for inclusion of a particular person to circle the individual objects of crime prevention should be, in our opinion, the commission of an administrative offense or the expiry of a person serving a sentence of imprisonment.

In addition, such a condition should be the fact of finding a minor crime in the microenvironment.

It seems that all this is likely the future of business, because bringing the Russian legislation in line with international legal instruments in terms of guarantees of human rights has just begun. However, now we need to start work on the creation of a set of legal rules governing the process of assigning a specific person to circle the individual objects of crime prevention.

\section{Summary and Conclusions}

Certain interest and the validity of the rights aspect of the issue of restrictions profilactic individualization of preventive interventions. Solving the problem of individualization of the measures individually-preventive effect is seen in the possibility of divisions individual forecasting expertise recommendations for use against a specific person a strictly defined set of interventions that would allow a maximum likelihood to prevent a person committing crimes.

All measures specially-criminological prevention of juvenile crime can be divided into three groups:

1) Safety improvement of the environment nearest residential environment and assistance to young people in difficult living conditions and upbringing before the criminogenic circumstances significantly affect their behavior: the appointment of a guardian (trustee), deprivation of parental rights: the direction of the parents in the treatment of alcoholism, children's room in a special school, a boarding school.

2) Prevention of crime and correction of minors who commit offenses that do not entail criminal punishment 
(«non-criminal nature»): registration in OPPN; consideration in the CLN placement in a special educational institution; indemnity for damages and more (Zhupik, 1985).

3) Penaltiesforminorcrimesandpreventthemfromcommittingrepeatedoffenses (recidivism) prevention of crime; criminal proceedings; preliminary investigation and trial in court (in KDN); education and rectification in prisons; labor and home appliance minors who have served their sentence.

The first group of preventive measures carried out by special (specialized) authorities, primarily commissions for juvenile affairs; bodies engaged in the education of children and adolescents (authorities and vocational education and training institutions, as well as the administration of enterprises and institutions, the public).

The second group of preventive measures carried out mostly by law enforcement agencies. Among them, a more active role played by the courts. The implementation of these measures is involved, and other specialized agencies (OPPN and district police inspector).

The third group of preventive measures carried out by the executive authorities and agencies mentioned above. Increasing the role of the court and the bodies of the preliminary investigation.

\section{Refrences}

Abizov, R. M. (1979). Prediction of criminal behavior and methodical bases of individual crime prevention. Diss. ... Cand. jurid. Sciences. M., S.16-35, 62-121.

Arutynyan, A. D., \& Valuiskov, N. V. (2014). Modern policy of fight against crime of minors. In the book: Modern science: theoretical and practical approaches to the Collection of articles of International scientific-practical conference. Research center "Aeterna". P188-190.

Avanesov, G. A. (1984). Criminology. M., pp 392-393.

Igoshev, K. E., \& Ustinov, V. S. (1977). Introduction to crime prevention course. Gorky, pp 43-44.

Kirillov, L. A. (1994). Individual crime prevention law-enforcement bodies. Tyumen, P. 38.

Korolenko, I. I. (1999). Criminological and prevention of crimes committed by minors without parental care. Diss. ... Cand. Law Sciences. Rostov-on-Don, P.116.

Minkovsky, G. M. (1972). The subject of criminological prevention of crimes and some problems of its effectiveness. Questions of combating crime, 17. M., P.16.

Pankratov, V. V. (1983). Juvenile delinquency: study and prevention. In the book: Questions of combating crime. Moscow, Vol. 38. P.21.

Pishikina, N. I. (1998). Legal and methodological issues of the prevention of juvenile delinquency. Author. ... Dis. cand. Law Sciences. M., P.14.

Sadkov, E. V. (1994). crime prevention in a marginal environment of young people. Author. ... Cand. jurid. Sciences. - M., P. 17.

Shlyapochnikov, A. S. (1972). On the classification of crime prevention measures. Questions of combating crime, 17. M., C.5.

Sundurov, F. P. (1983). Juvenile delinquency and prevention. Kazan, pp 130.

Valuiskov, N. V., Bondarenko, L. V., \& Rokotyanskaya, V. V. (2012). To a question about the prospect of improving the legal framework for the prevention of social deviations in youth and adolescents as a priority social policy. Theory and practice of social development, (2), 346-349.

Zakalyuk, A. P. (1986). Prediction and prevention of individual criminal behavior. - M.

Zakalyuk, A. P. (1989). Methodology Individual prediction of criminal behavior. Methodology and methods of forecasting in the fight against crime. Proceedings of the Academy of Ministry of Internal Affairs of the USSR. M., pp 69-72.

Zhalinsky, A. E. (1976). Special prevention of crimes in the USSR (questions of the theory). Lvov, 95.

Zhupik, A. E. et al. (1985). juvenile delinquency and prevention. Riga, 85 pp.

\section{Copyrights}

Copyright for this article is retained by the author(s), with first publication rights granted to the journal.

This is an open-access article distributed under the terms and conditions of the Creative Commons Attribution license (http://creativecommons.org/licenses/by/4.0/). 